\title{
Cellulose acetate honeycomb-like pattern created by improved phase separation
}

\author{
K. Neznalová ${ }^{1}$, P. Sajdl ${ }^{2}$, V. Švorčik ${ }^{1}, P$. Slepička ${ }^{1 *}$ \\ ${ }^{1}$ Department of Solid State Engineering, The University of Chemistry and Technology, 16628 Prague, Czech Republic \\ ${ }^{2}$ Department of Power Engineering, The University of Chemistry and Technology, 16628 Prague, Czech Republic
}

Received 17 March 2020; accepted in revised form 7 May 2020

\begin{abstract}
The goal of this work was to prepare a honeycomb-like pattern (HCP) structure by a combination of acetate cellulose and poly-L-lactic as biocompatible and biodegradable polymers used in tissue engineering. The formation was obtained by a fast and cheap solution-immersion phase separation method based on the presence of nonsolvent, which induces phase separation in normal air without surfactants and supports the formation of the honeycomb structure. As a substrate, we used plasma modified fluorinated polymer, which can significantly improve the possibility of successful preparation HCP formation and control pore size and dimension of the prepared porous layer. Honeycomb-like pattern structure from composite acetate cellulose-PLLA on the surface of plasma-treated perfluorinated polymer FEP was prepared with a simple technique. Plasma modification changed the surface chemistry, wettability and thus allowed the creation of HCP microporous structure on the perfluorinated substrate. The regularity, surface morphology, and wettability of HCP film can be effectively controlled by changing of plasma activation.
\end{abstract}

Keywords: biopolymers, cellulose acetate, honeycomb pattern, PLLA, surface morphology

\section{Introduction}

Cellulose is generally considered as the most widespread organic polymer on our planet. It is a cheap renewable resource because it is not only a part of higher plant cell walls but is also synthesized by most groups of algae, several bacteria, and tunicates [1]. Biocompatibility, low toxicity - essential features for biomedical utilization make cellulose and its various modifications a great deal of interest. Cellulose has the potential to fulfill the requirements for a suitable biomaterial in tissue engineering, such as derived from a sustainable source, and which requires minimal processing to achieve cell viability for industrial applications [2]. Many studies are published on this subject every year, which seeks to clarify other uses and marketing of this substance [3]. However, to use cellulose as a scaffold in tissue engineering, it is necessary to add ligands to cellulose matrix
[4] or the introduction of a surface charge on cellulose film $[5,6]$ to facilitate cell attachment to their surfaces. Plant and bacterial cellulose and their modifications hold promise for tissue engineering [7]. Bacterial cellulose has a similar structure as the plant cellulose, but it can be prepared without contaminants and was used for tissue engineering studies [810]. Cellulose-based scaffolds functionalized with chitosan improve the adhesion and growth of several types of cells [11-13]. Plasma treatment to improve the surface properties of cellulose acetate [14], cellulose fibers [15], and bacterial cellulose [16] is widely used in tissue engineering.

Moreover, cellulose is a non-degradable or very slowly degradable material in the human body [33]. Therefore, its modification is necessary. The advantage of cellulose is facile functionalization as it bears oxygencontaining groups in different cellulose derivatives

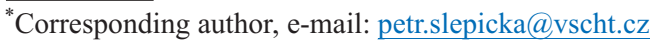
(C) BME-PT 
[17-19]. Chemical modification of cellulose may also be realized by nucleophilic reactions at the carbon atoms [29]. Moreover, oxidation of cellulose to introduce carbonyl- or carboxyl groups has also found permanent interest [20, 21]. It exists several techniques to obtain various forms and shapes of cellulose (e.g. electrospinning, melt blowing, freezedrying), which are used in tissue engineering from commercially available viscose fibers, nonwovens, films, composites to advanced and functionalized materials [22]. Viscose cellulose sponges have been investigated for their biocompatibility with the bone tissue [23] and also as scaffolds for cartilage tissue engineering [24]. Fibrous cellulose templates activated in $\mathrm{Ca}(\mathrm{OH})_{2}$ and coated with hydroxy carbonated apatite, and injectable cellulose-based hydrogels have been successfully tested as carriers for chondrocytes for in vitro cartilage tissue engineering [25, 26]. Regenerated cellulose has been used for constructing 3D tissue with capillaries [27] and together with cellulose acetate also for cardiac tissue engineering [28]. This article [30] reviewed cellulose derivatives for vascular tissue engineering. Furthermore, cellulosic materials with defined nanoscale structural dimensions called 'nanocellulose' can also be prepared. Nanocellulose materials can be mainly of three types - cellulose nanocrystals (CNC), cellulose nanofibers (CNF), or bacterial nanocellulose (BNC). The shape and properties of the nanostructures are dependent on the source of the cellulose as well as the applied treatment. The comparison in terms of production, properties, and biomedical applications is reviewed in this article [31].

Poly-L-lactic acid is a common synthetic biocompatible polymer with tunable mechanical properties, which is widely used to prepare biodegradable scaffolds for a range of applications in tissue engineering. Many studies of cellulose-PLLA composite used have been reported [32].

There are several extensive reviews of the applications of the porous films [34], which are usually called 'honeycomb-patterned films' (HCP) because their hexagonally packed porous structure resembles honeycombs. Honeycomb formation can be used in medicine, especially in anti-bacterial activity [35], tissue engineering [36, 37], protein absorption [38], drug delivery [39]. Honeycomb-patterned cellulose films were for the first time fabricated in 2003 [40]. Since then, the honeycomb structure from cellulose and its derivatives has been prepared by several methods (transcription [41], mimicking the wood cell wall formation [42], breath figure method [43],) on different substrates (e.g. glass, ice [43], nanofiber [44]). The breath figure process is an example of a self-assembly procedure that forms honeycomb-structured films with the assistance of water vapor droplets [45]. The disadvantage of this method is the requirement of very humid conditions, which limit the industrial potential and application of honeycomb films [46]. Recently Bui et al. [47] reported a simple onestep method based on improved phase separation. Using this method, the presence of humidity and surfactants is not necessary, and a highly ordered HCP structure can be prepared. Honeycomb films can be prepared on hydrophilic substrates, including glass, metals, and also organic solid substrates, including fluorinated polymers [34].

In our previous research [48], we have successfully prepared honeycomb structure from poly-L-lactic acid on chemically, and heat resistant polymer perfluoroethylene propylene (FEP) using plasma surface pre-treatment and showed the possibility to add cellulose into the matrix. In this study, we have applied an improved phase separation method for the preparation of honeycomb structure from the combination of cellulose acetate and poly-L-lactic acid on fluorinated polymer for potential application in cell culture. In particular, this solid substrate with the HCP could be tested for cytocompatibility as a scaffold for antibacterial release after doping with metal nanoparticles or used as a drug delivery system.

\section{Experimental}

\subsection{Materials}

We used commercially available acetate cellulose (AcetCel, in powder form, $M_{\mathrm{n}}=30000$, density $1.3 \mathrm{~g} \cdot \mathrm{cm}^{-3}$, supplied by Sigma-Aldrich, USA) and poly-L-lactic acid (PLLA, $M_{\mathrm{n}}=20000,50 \mu \mathrm{m}$ thick foil, density $1.25 \mathrm{~g} \cdot \mathrm{cm}^{-3}$, supplied by Goodfellow Ltd., Great Britain). As a solvent, we used chloroform $\left(\mathrm{CHCl}_{3}\right.$, stabilized with $1 \%$ ethanol $\mathrm{AG}$, received from Penta, Czech Republic) and methanol $(\mathrm{MeOH}$, for HPLC, received from Penta, Czech Republic). As a substrate, we used perfluoroethylene propylene polymer (FEP, $50 \mu \mathrm{m}$ thick foil, density $2.15 \mathrm{~g} \cdot \mathrm{cm}^{-3}$, supplied by Goodfellow Ltd., Great Britain). We used Pt target (purity 99.9995\%, SAFINA, Czech Republic) for deposition of conductive layer for analysis. 


\subsection{Plasma modification of the substrate}

FEP foils were treated in diode plasma discharge [49] using Balzers SCD 050 device (Baltec) by lowtemperature DC Ar plasma. The gas purity used was $99.997 \%$, the Ar flow was set to $0.31 \cdot \mathrm{s}^{-1}$, and the gas pressure was $10 \mathrm{~Pa}$ and input power $8 \mathrm{~W}$. The modification was realized under pressure $8 \mathrm{~Pa}$, the distance of electrodes was $50 \mathrm{~mm}$ with the area of $48 \mathrm{~cm}^{2}$ and plasma volume of $240 \mathrm{~cm}^{3}$. The plasma treatment of the samples was accomplished at room temperature, and the exposure time was set to 40 and $240 \mathrm{~s}$ [50].

\subsection{Preparation of honeycomb-patterned structure}

The binary mixture of chloroform ('good' solvent) and methanol ('bad solvent') in volume $100 \mathrm{ml}$ and volume ratio $85 / 15$ was prepared through mixing two liquids. The process was realized at room temperature. Adding $2 \mathrm{~g}$ cellulose acetate (or optionally $2 \mathrm{~g}$ cellulose acetate and $2 \mathrm{~g}$ PLLA) to a mixture of solvents and stirring continuously for $24 \mathrm{~h}$ was obtained the homogenous solution. The HCP was created by the solvent-immersion phase separation method using dip-coating. Prepared plasma modified substrate was dipped into the mixture solvent for $10 \mathrm{~s}$, and then it was withdrawn and left in the air to complete evaporation of the solvents. The air-drying process was accomplished for 10 minutes at an ambient atmosphere then the samples were transferred into a plastic box.

\subsection{Characterization}

The surface morphology and roughness of modified polymer samples were examined by the atomic force microscopy (AFM) and laser confocal microscopy. For AFM analysis, we used Dimension ICON (Bruker Corp.), QNM mode in the air was used for determination. Silicon tip on nitride lever SCANASYSTAIR with spring constant $0.4 \mathrm{~N} \cdot \mathrm{m}^{-1}$ was used [48]. For confocal microscopy, we used an Olympus Lext OLS3100 device. For the LCM analysis, the Olympus LEXT OLS 3100 microscope was chosen with the blue laser $(\lambda=407 \mathrm{~nm})$ and with the magnification up to $14400 \times$.

The surface morphology and elemental composition were acquired with a scanning electron microscope (SEM) and energy-dispersive X-ray spectroscopy (EDS). We used LYRA3 device (Tescan, Czech Republic) with applied acceleration voltage $10 \mathrm{kV}$ for SEM and F-MaxN analyzer and SDD detector (Oxford Instruments, UK) with applied acceleration voltage $10 \mathrm{kV}$ for EDS. The samples were covered with the Pt conductive layer of $20 \mathrm{~nm}$ thickness by a diode sputtering method (Quorum Q300T).

The presence of oxygen, carbon, and fluorine in the surface layer was determined by X-ray photoelectron spectroscopy (XPS). An Omicron Nanotechnology ESCAProbeP spectrometer was used. The exposed and analyzed area had a dimension of $2 \times 3 \mathrm{~mm}^{2}$ [51]. The X-ray source was monochromatic at $1486.7 \mathrm{eV}$. Atomic concentrations of elements were determined by CASA XPS program. The samples were analyzed under take-off angle $19^{\circ}$.

The surface wettability was determined by goniometry using a static water drop method. The measurements of water contact angles were performed using distilled water (error $\pm 5 \%, 6$ different positions) using the Surface Energy Evaluation System (SEE System, Advex Instruments, Czech Republic) [52]. By automatic pipette, the water drop of volume (8.0 \pm 0.2$) \mu 1$ was deposited on the sample, and the consequent photo was evaluated. The measurement was performed immediately after the modification at room temperature.

\section{Results and discussion}

\subsection{Surface morphology and roughness}

The preparation of honeycomb-pattern film on pristine FEP foil was not successful. Modification by plasma discharge, which we used in our previous investigation [48], activated the polymer surface and improved the possibility of HCP structure on polymer FEP compared to pristine foil. The surface morphology, roughness, and effective surface area of modified foils were determined by AFM. Nanostructure or microstructure properties may play a significant role in substrate biocompatibility $[49,53,54]$. The AFM scans are listed in Figure 1. Images of pristine FEP and plasma-treated foil are available in paper [55]. The plasma-treated FEP foils were immersed into the cellulose acetate and cellulose acetate-PLLA. The optimal honeycomb-like pattern structure was achieved by choosing a combination of cellulose acetate, and PLLA on FEP treated $240 \mathrm{~s}$ (see Figure 1d). This structure was ordered with the highest surface area (difference 147.0\%) and the highest roughness $(931.0 \mathrm{~nm})$. We can say that for the same exposure time, the pore size is different - cellulose acetate layer formed as smaller disordered pores instead of cellulose acetate-PLLA layer formed with larger pores in the structure. In Figure 1c we can see 


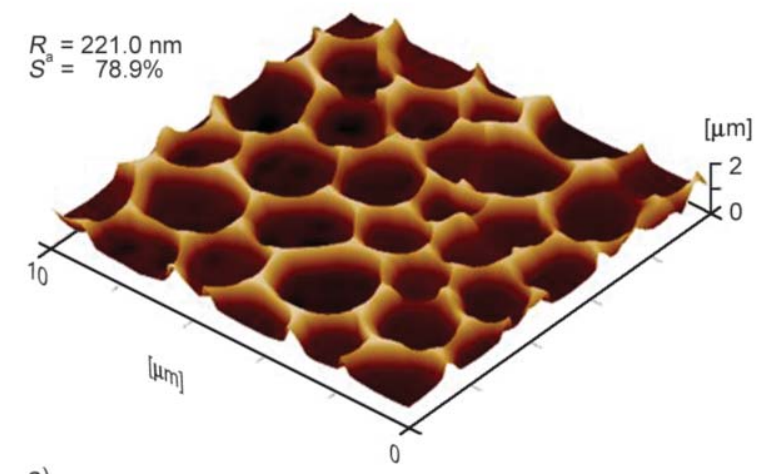

a)

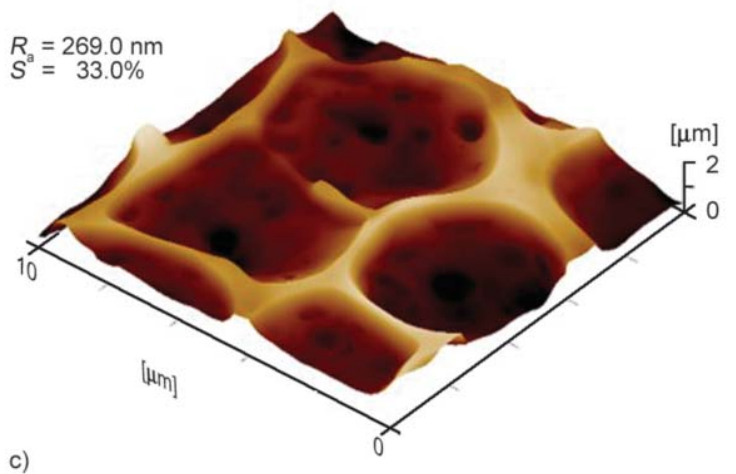

b)
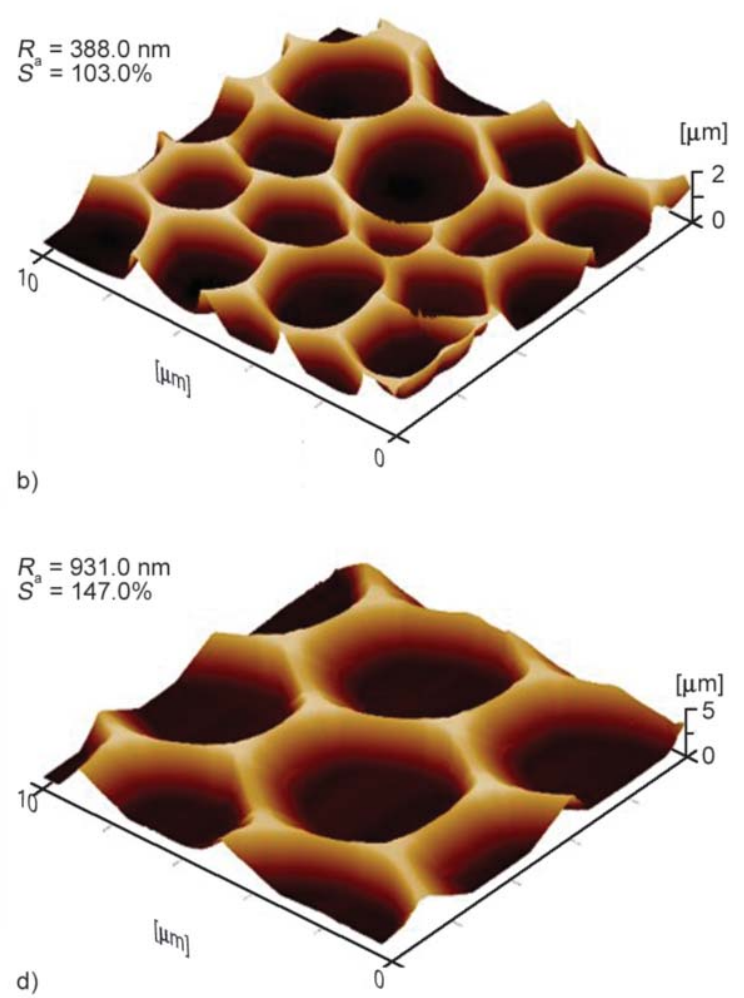

Figure 1. 3D AFM images of surface morphology and roughness of HCP acetate cellulose on - (a) FEP treated by plasma $8 \mathrm{~W}$ and $40 \mathrm{~s}$, (b) FEP treated by plasma $8 \mathrm{~W}$ and $240 \mathrm{~s}$ and HCP acetate cellulose-PLLA on - (c) FEP treated by plasma $8 \mathrm{~W}$ and $40 \mathrm{~s}$, (d) FEP treated by plasma $8 \mathrm{~W}$ and $240 \mathrm{~s}$. The inspected area is $10 \times 10 \mu \mathrm{m}^{2} . R_{\mathrm{a}}$ represents arithmetic mean surface roughness.

small dimples in FEP foil. By higher exposure time, the roughness and surface area increased on both foils, on acetate cellulose-PLLA rapidly $(931.0 \mathrm{~nm}$, $147 \%$ ). The size and dimension of pores can be controlled by plasma treatment parameters and selected polymer/polymer combination. It is evident, that by higher plasma exposure time we obtained surface with higher roughness as well as higher surface area and higher regularity of the pattern.

The surface morphological changes induced by plasma treatment and subsequent biopolymer coating were also observed by analysis with laser confocal microscopy (see Figure 2). The obtained results corresponded to the results determined by AFM microscopy. The size of the pores was larger on samples with acetate cellulose-PLLA honeycomb pattern than on acetate cellulose sample. In Figure 2c, the sample treated by plasma for $40 \mathrm{~s}$ and subsequently coated with acetate cellulose-PLLA has irregular pores which are not all isolated from each other compared to the sample exposed for $240 \mathrm{~s}$ (see Figure 2d), where we can see isolated hexagonal pores. However, it is obvious that the regularity of units is not the same over the entire polymer surface. The pattern with pores of different sizes was prepared (dimensions in the range
$1-5 \mu \mathrm{m})$. The previous AFM scans represent the area with a pore size of approximately $4 \mu \mathrm{m}$. But, the presence of units in interval 1-5 $\mu \mathrm{m}$ can be useful for cell attachment, as well as also observed visible secondary microstructures, especially on samples dipped in composite acetate cellulose-PLLA. The different pore dimensions may arise from the process itself, where areas of slightly different phase separation take place.

\subsection{Surface topography and elemental mapping}

The SEM scans (see Figure 3) confirmed the results obtained from AFM. The character of the pore walls is more authentic in SEM images because the high structures are not distorted by AFM tip or affected by somewhat higher wavelength and optical noise induced by laser confocal microscopy. After deposition of acetate cellulose-PLLA microporous layer (see Figure 3c, 3d), the pore size increases. In Figure $3 \mathrm{c}$ we observe small dimples in FEP foil confirmed thus AFM and confocal microscopy results. As illustrated in Figure 3d, the combination of longer time of plasma exposition and the mixture of acetate cellulose-PLLA led to regular hexagonal pattern with a size of pore approximately $4 \mu \mathrm{m}$. 


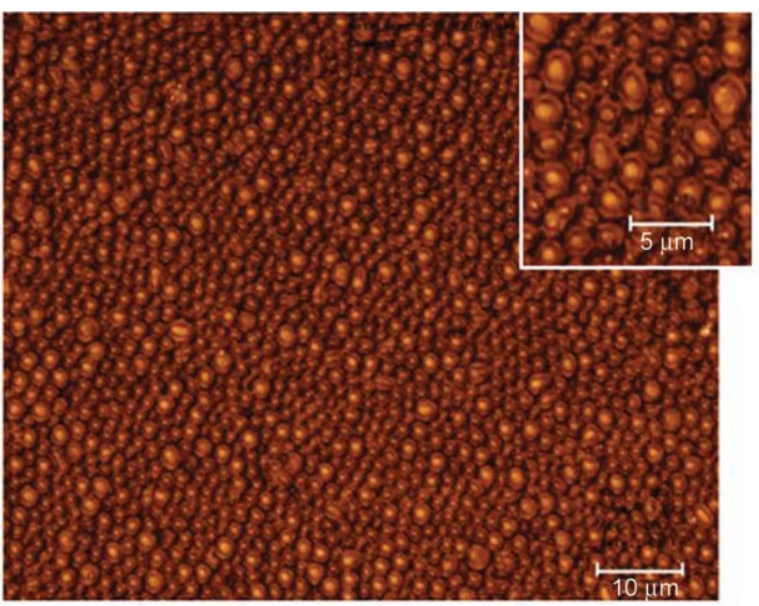

a)

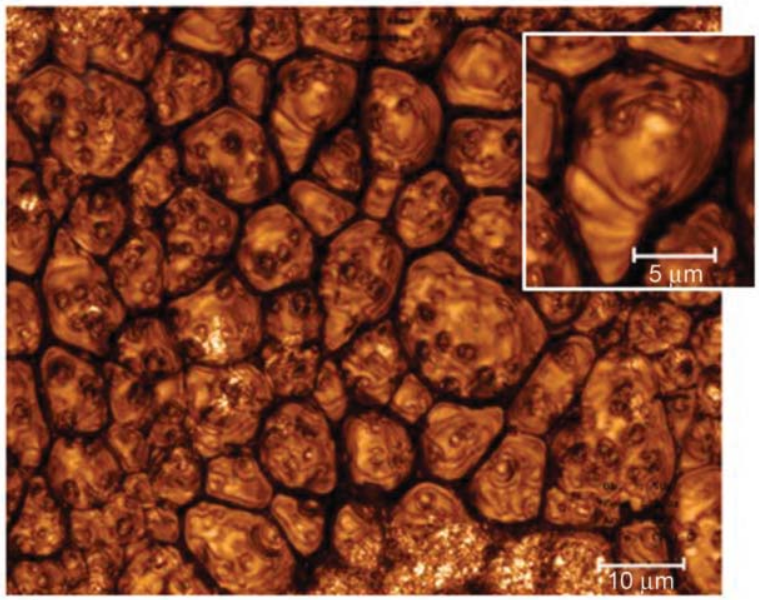

c)

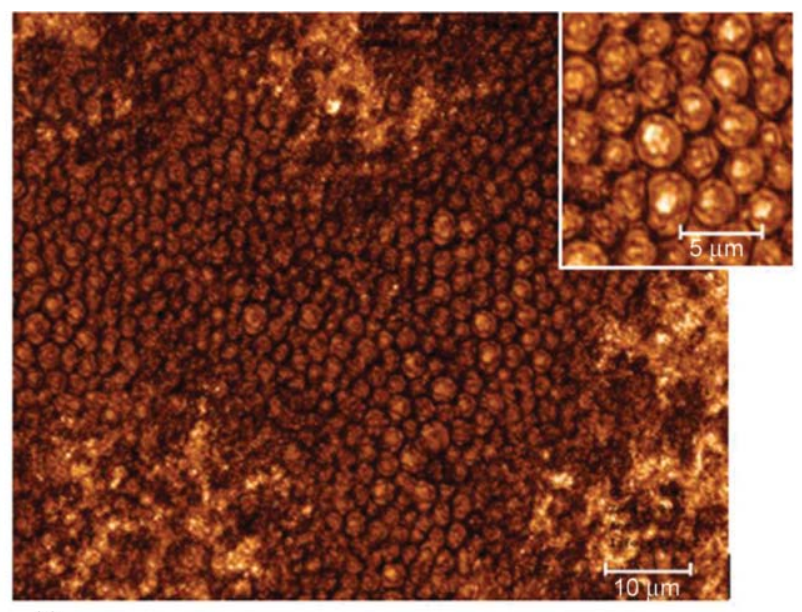

b)

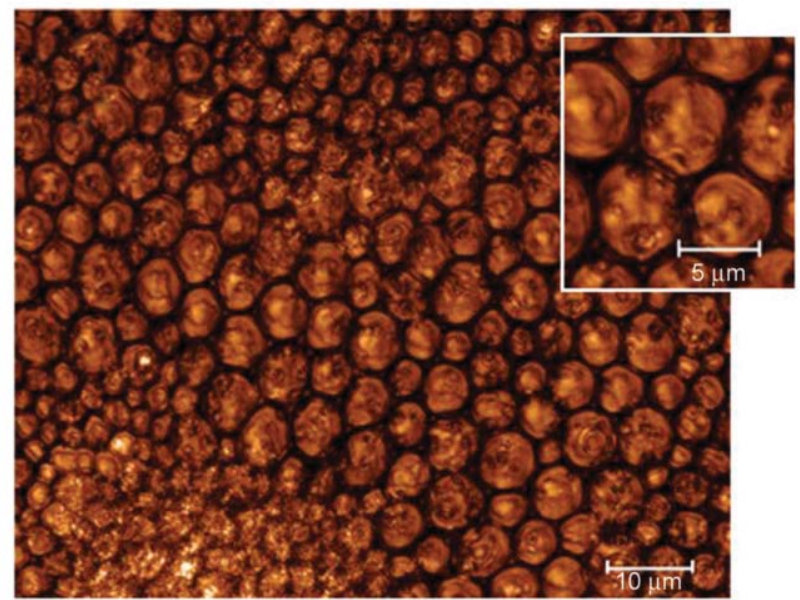

d)

Figure 2. 2D images of HCP acetate cellulose structure on - (a) FEP treated by plasma $8 \mathrm{~W}$ and $40 \mathrm{~s}$, (b) FEP treated by plasma $8 \mathrm{~W}$ and $240 \mathrm{~s}$ and HCP acetate cellulose-PLLA on - (c) FEP treated by plasma $8 \mathrm{~W}$ and $40 \mathrm{~s}$, (d) FEP treated by plasma $8 \mathrm{~W}$ and $240 \mathrm{~s}$.

The surface mapping of elements $(\mathrm{C}, \mathrm{F}, \mathrm{O})$ was evaluated by EDS, which allows us detecting in detail the success of pattern formation. We can observe the best visible elemental distribution in Figure 3aI-III. From Figure 3 aII it is evident that fluorine distribution follows the hexagonal pattern, the pattern areas exhibit significantly lower fluorine signal, and it is in excellent agreement with the patterned topography. It is obvious that the fluorine signal arises from the FEP substrate only, whereas carbon and oxygen are contained in both, FEP foil and in the walls of structure (see Figure 3aI, 3aII).

\subsection{Surface wettability}

The water contact angle was determined immediately after the modification. We investigated the influence of plasma treatment and the coated layer on the surface wettability of samples (see Figure 4). The pristine FEP contact angle was determined to be $104.4^{\circ}$. After plasma treatment, the contact angle decreases rapidly for both exposure time in comparison to pristine foil. This decrease was caused by the reaction of radicals and newly formed oxygen functional groups induced by plasma modification with the atmosphere. The values of contact angle correspond with surface element concentration of oxygen and fluorine - higher concentration of oxygen and a lower concentration of fluorine led to higher wettability. For $8 \mathrm{~W}$ input power and $240 \mathrm{~s}$ exposure time, the value of contact angle dropped to $34.1^{\circ}$, which was approx. half of the value of FEP treated for a shorter time (40 s), value slightly lower comapred to [55]. This value of the contact angle was the lowest from the studied samples. A similar trend was observed for foils dipped by cellulose acetate as well as with a combination of PLLA. FEP treated with $40 \mathrm{~s}$ was determined as a surface with higher hydrophobicity in comparison to treatment $240 \mathrm{~s}$. The addition of PLLA to cellulose acetate reduced the contact angle of the prepared pattern. The images of the contact angle for 

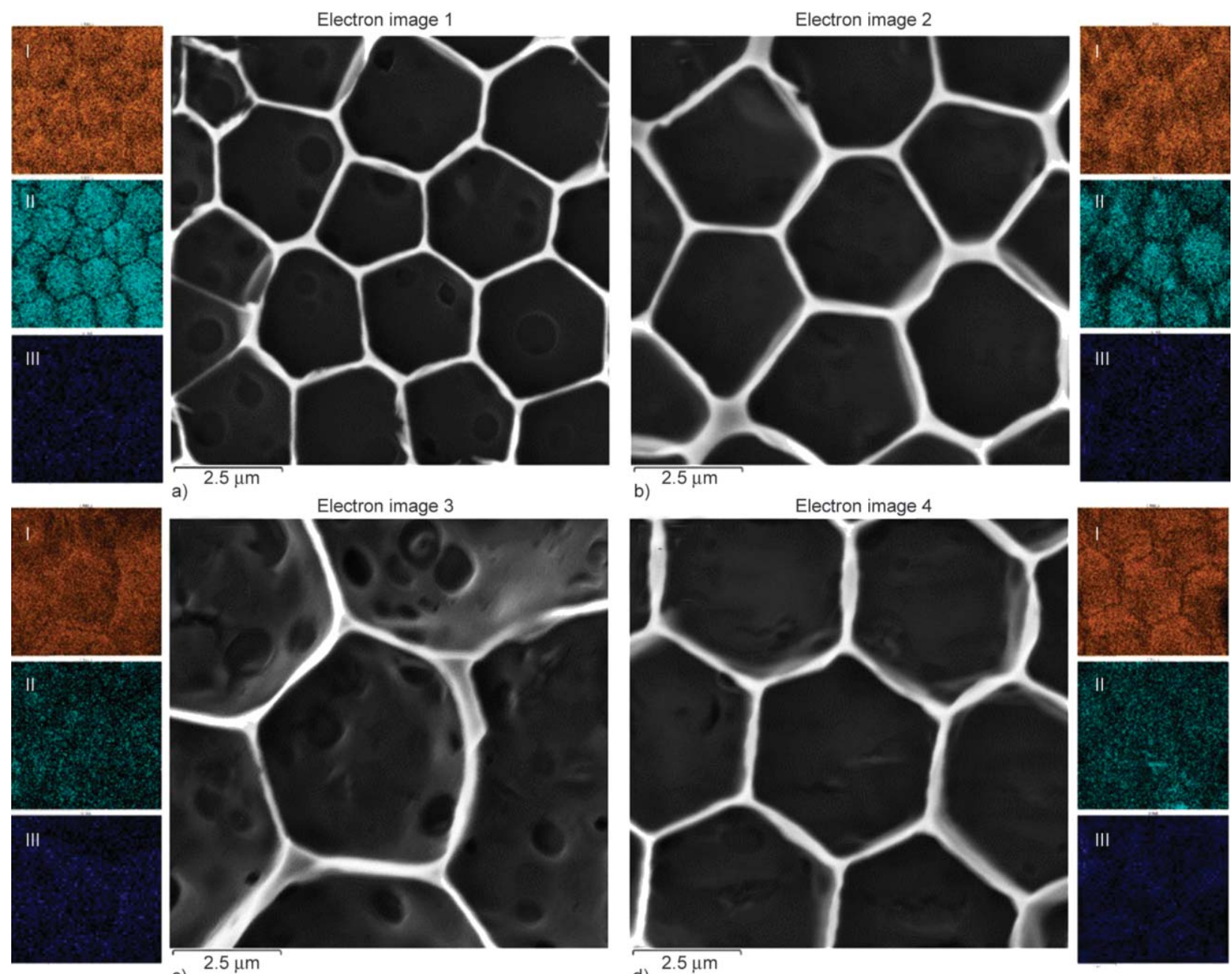

c) $2.5 \mu \mathrm{m}$
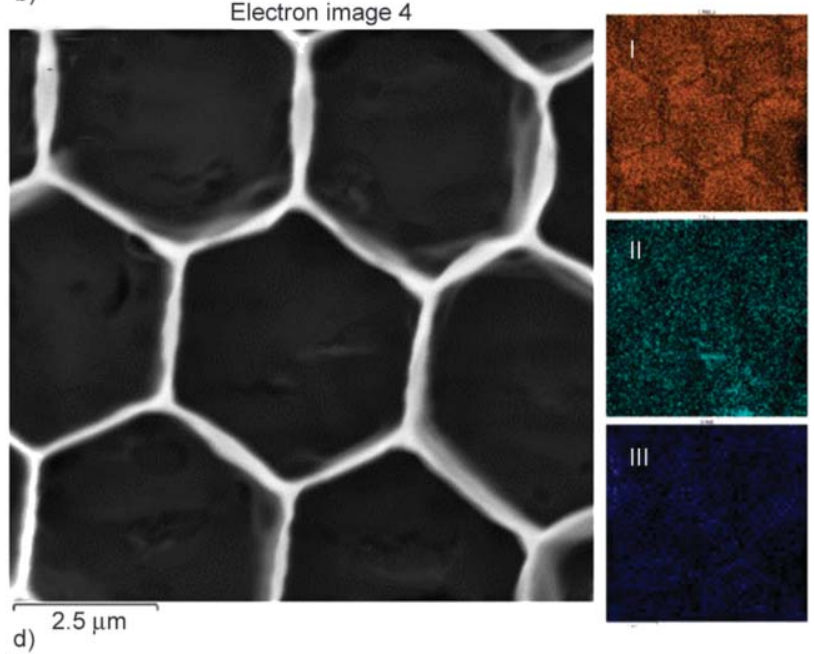

Figure 3. SEM scans and complemented EDS elemental mapping (I) - carbon, (II) - fluorine, (III) - oxygen of HCP acetate cellulose structure on - (a) FEP treated by plasma $8 \mathrm{~W}$ and $40 \mathrm{~s}$, (b) FEP treated by plasma $8 \mathrm{~W}$ and $240 \mathrm{~s}$; and HCP acetate cellulose-PLLA on - (c) FEP treated by plasma $8 \mathrm{~W}$ and $40 \mathrm{~s}$, (d) FEP treated by plasma $8 \mathrm{~W}$ and $240 \mathrm{~s}$. The inspected area is $10 \times 10 \mu \mathrm{m}^{2}$.

particular modification are shown in Figure 4. With higher exposure time, we have observed lower hydrophobicity of the polymer surface. From Figure 4, it is evident that the modification by plasma discharge and coating with additional acetate cellulose layer influence surface wettability of the pattern. The plasma treatment of FEP led to increasing of wettability as well as FEP with cellulose acetate and a mixture of cellulose acetate-PLLA prepared by dip-coating. The PLLA in cellulose acetate led to a decrease of contact angle compared with the cellulose layer only. Similar values of contact angle as for acetate cellulose-PLLA on plasma-treated FEP were observed for cellulose acetate derivatives, with increasing degree of acyl substitution and the number of carbon in acyl substitution the contact angle increased from ca $65^{\circ}$ to ca $95^{\circ}$ [56]. Addition of PLLA into acetate cellulose led due to change of foil chemistry to modification of surface properties and wettability, the influence of various bioactive components on surface wettability was also confirmed in [57].

\subsection{Surface chemistry}

The chemical composition of prepared honeycomblike structures or the plasma-treated substrate itself was investigated by XPS, and the results are listed in Table 1. This method provides information about differences in element concentration. The surface element concentration was measured up to 6-8 atomic layers from the surface. Pristine FEP contained 33.2\% of carbon and $66.8 \%$ of fluorine. Plasma treatment induced the formation of oxygen-containing groups, while the concentration of fluorine decreased [55]. With higher plasma exposure time, the oxygen concentration increased significantly (up to 14.5\%). Due to the immersion procedure of activated FEP into 


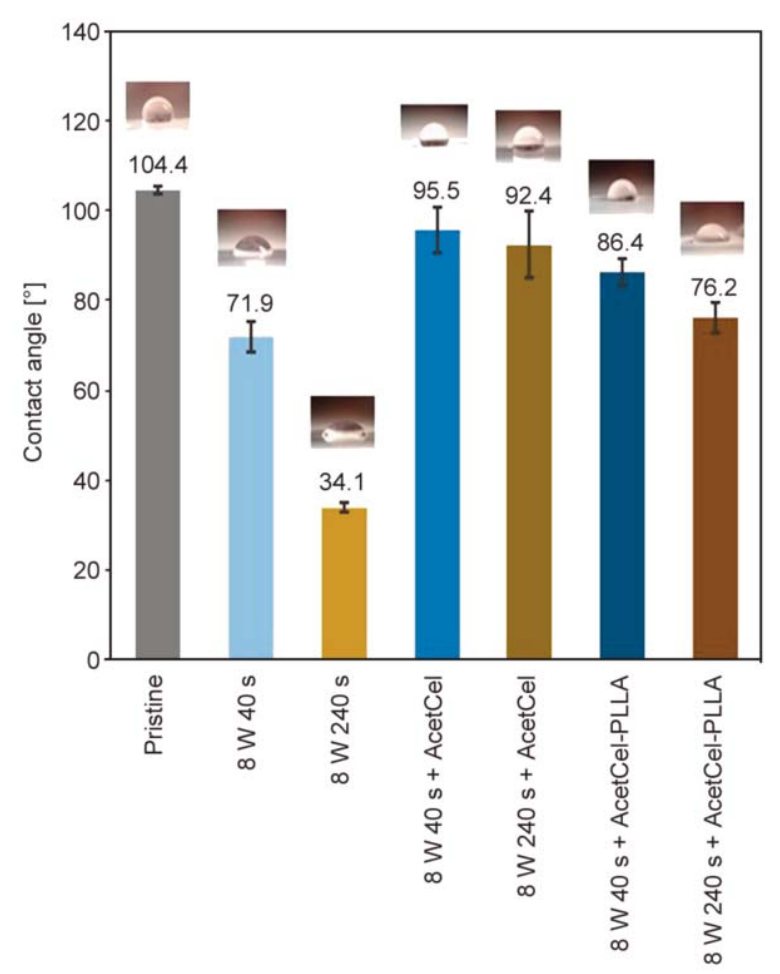

Figure 4. The values and images of water contact angle of pristine FEP, FEP after plasma treatment (power $8 \mathrm{~W}$, exposure time 40 and $240 \mathrm{~s}$ ), and applying acetate cellulose and acetate cellulose-PLLA.

cellulose acetate and cellulose acetate-PLLA, we detected no fluorine and pronounced oxygen increase was detected, which implicated the continuous biopolymer formation. With the XPS method, it was detected that a small amount of nitrogen is introduced onto the FEP surface (1.7-2.2\%) for selected samples. The nitrogen in the treated polymer was introduced into the polymer after plasma activation from the atmospheric nitrogen due to reaction with surface radicals, and plasma activation has the key role for subsequent nitrogen attachment. Plasma treatment also induces surface oxygen concentration increase, which is followed with the same trend for subsequently created polymeric layer by dip coating. Also, from AFM analysis, it can be concluded that the surface with higher roughness corresponds to higher oxygen concentration.

This method also provided information about the creation of new functional groups. Selected C(1s) spectra of FEP treated by plasma discharge and then coated with acetate cellulose or acetate cellulosePLLA composite are introduced in Figure 5. The deconvolution of $\mathrm{C}(1 \mathrm{~s})$ spectra present the chemical bonds between carbon and other atoms on the surface. The maximum for the carbon $\mathrm{C}(1 \mathrm{~s})$ spectrum of acetate cellulose (see Figure 5a) was determined to be at binding energy $286.5 \mathrm{eV}$, the peak of functional group $\mathrm{C}-\mathrm{O}-\mathrm{H} / \mathrm{C}-\mathrm{O}-\mathrm{C}$. The binding energy related to non-polar carbon bonds like $\mathrm{C}-\mathrm{H}, \mathrm{C}-\mathrm{C}$ (carbon with no oxygen bonding) can be found at position $285 \mathrm{eV}$ and the carboxyl bonds such as $\mathrm{C}(=\mathrm{O})-\mathrm{O}$ can be found at the highest binding energy $289 \mathrm{eV}$ and carbonyl bonds like $\mathrm{O}-\mathrm{C}-\mathrm{O} / \mathrm{C}=\mathrm{O}$ at binding energy $288 \mathrm{eV}$. The position of the peaks is in good comparison obtained in [58]. We can see two other peaks of low binding energy, at approximately 282.5 and $281.0 \mathrm{eV}$. These peaks represent areas with heterogeneous conductivity. A difference was determined on the FEP treated $240 \mathrm{~s}$ with acetate cellulose microstructure, where the major peaks are not carbonyl or carboxyl, but non-polar carbon bonds, which would suggest partial revealing of the substrate itself. The addition of PLLA to polymer solution led to minor changes in the carbon $\mathrm{C}(1 \mathrm{~s})$ spectra.

The amount of functional groups found on treated surfaces and characterized by XPS was calculated and is reported in Table 2. The content of the carbonyl group, which was found on the treated surfaces, was correlated with the wettability of treated surfaces. It is evident, if we consider the oxygen amount from Table 1, that the increasing trend of oxygen concentration is in good correspondence with decreasing contact angle (Figure 4). However, if we analyze the particular amount of oxygen-containing groups, we can see a decrease of $\mathrm{O}-\mathrm{C}-\mathrm{O} / \mathrm{C}=\mathrm{O}$ group for analyzed samples, but clear identification between the sum of the carbonyl group and wettability trend is difficult to find (see Table 2); therefore we can conclude that probably surface oxygen radicals or surface roughness may also influence the surface wettability.

Table 1. Element concentration of polymer surface. The C, $\mathrm{O}, \mathrm{F}$, and $\mathrm{N}$ concentration (in at.\%) were determined by the XPS method for pristine FEP, samples treated by plasma discharge (power $8 \mathrm{~W}$, exposure time 40 and $240 \mathrm{~s}$ ) and samples with acetate cellulose layer and acetate cellulose-PLLA.

\begin{tabular}{|l|c|c|c|c|}
\hline & \multicolumn{5}{|c|}{$\begin{array}{c}\text { Concentration of elements } \\
\text { [at.\%] }\end{array}$} \\
\hline \multicolumn{1}{|c|}{ Modification } & C & O & F & N \\
\hline FEP pristine & 33.2 & - & 66.8 & - \\
\hline FEP 8 W 40 s & 35.6 & 9.8 & 54.6 & - \\
\hline FEP 8 W 240 s & 37.4 & 14.5 & 46.4 & 1.7 \\
\hline FEP 8 W 40 s + AcetCel & 62.9 & 34.9 & - & 2.2 \\
\hline FEP 8 W 240 s + AcetCel & 62.0 & 38.0 & - & - \\
\hline FEP 8 W 40 s + AcetCel-PLLA & 61.3 & 38.7 & - & - \\
\hline FEP 8 W 240 s + AcetCel-PLLA & 59.9 & 40.1 & - & - \\
\hline
\end{tabular}



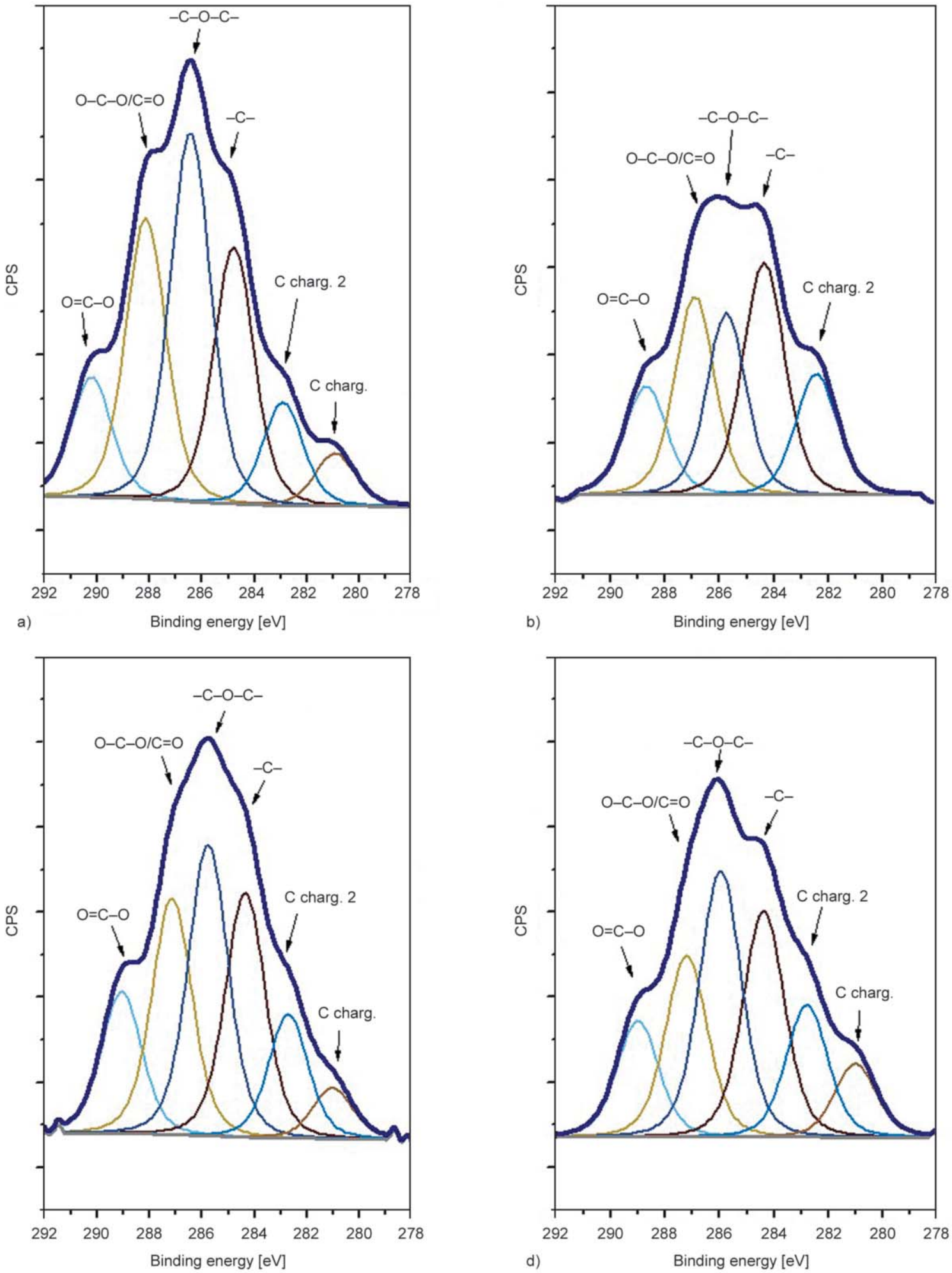

Figure 5. Carbon C(1s) XPS spectra (measured and fitted) of HCP acetate cellulose layer on (a) FEP 8 W/40 s, (b) FEP $8 \mathrm{~W} / 240 \mathrm{~s}$; and HCP acetate cellulose-PLLA layer on - (c) FEP 8 W/40 s, (d) FEP 8 W/240 s.

\section{Conclusions}

We have prepared the honeycomb-like pattern structure from composite acetate cellulose-PLLA on the surface of plasma-treated perfluorinated polymer FEP in an easy and effective way. Plasma modification changed the surface chemistry, wettability and allowed the creation of HCP microporous structure on FEP foil. The regularity, effective surface area, and wettability of HCP film can be effectively controlled through parameters of plasma modification. The shape and order of pores changed significantly, if we used higher exposure time with the same plasma 
Table 2. Amount of detected chemical group on studied samples: acetate cellulose layer on (A) FEP $8 \mathrm{~W} / 40 \mathrm{~s}$, (B) FEP $8 \mathrm{~W} / 240 \mathrm{~s}$; and HCP acetate cellulose-PLLA layer on - (C) FEP $8 \mathrm{~W} / 40 \mathrm{~s}$, (D) FEP $8 \mathrm{~W} / 240 \mathrm{~s}$.

\begin{tabular}{|l|c|c|c|c|}
\hline \multirow{2}{*}{ Chemical group } & \multicolumn{4}{|c|}{$\begin{array}{c}\text { Amount for samples A-D } \\
\text { [in \%] }\end{array}$} \\
\cline { 2 - 5 } & A & B & C & D \\
\hline $\mathrm{O}=\mathrm{C}-\mathrm{O}$ & 10.2 & 13.4 & 14.2 & 11.7 \\
\hline $\mathrm{O}-\mathrm{C}-\mathrm{O} / \mathrm{C}=\mathrm{O}$ & 23.8 & 23.0 & 22.2 & 18.2 \\
\hline$-\mathrm{C}-\mathrm{O}-\mathrm{C}-$ & 31.2 & 20.9 & 26.6 & 26.8 \\
\hline$-\mathrm{C}-$ & 21.7 & 28.1 & 21.9 & 22.8 \\
\hline C charg. & 4.4 & - & 4.3 & 7.3 \\
\hline C charg. 2 & 8.7 & 14.6 & 10.8 & 13.2 \\
\hline
\end{tabular}

power. The detailed morphological structure, roughness, and effective surface area were determined by AFM, SEM, and laser confocal microscopy. The EDS elemental mapping confirmed the construction of honeycomb pattern with carbon maxima in the pattern ridges and fluorine increase in the pattern basis. The elemental analysis from XPS reveals the detailed structure of the top layers of constructed micro pattern both for acetate-cellulose or the structure combined with poly-L-lactic acid. The proposed approach presented a robust technique for heterogeneous honeycomb pattern formation with high application in the field of tissue engineering, where also the ability of PLLA to degrade and cellulose ability to be an excellent tissue carrier may be used. The prepared substrates will be tested in vitro for potential application as a scaffold in tissue engineering or case of nanoparticle incorporation and targeted release as antibacterial carriers.

\section{Acknowledgements}

This work was supported by the GACR under project 1902495S.

\section{References}

[1] Klemm D., Heublein B., Fink H. P., Bohn A.: Cellulose: Fascinating biopolymer and sustainable raw material. Angewandte Chemie, 44, 3358-3393 (2005). https://doi.org/10.1002/anie.200460587

[2] Miyamoto T., Takahashi S-I., Ito H., Inagaki H., Noishiki Y.: Tissue biocompatibility of cellulose and its derivatives. Journal of Biomedical Materials Research, 23, 125-133 (1989). https://doi.org/10.1002/jbm.820230110

[3] Hickey R. J., Pelling A. E.: Cellulose biomaterials for tissue engineering. Frontiers in Bioengineering and Biotechnology, 7, 45/1-45/15 (2019). https://doi.org/10.3389/fbioe.2019.00045
[4] Singh N., Rahatekar S. S., Koziol K. K. K., Sky Ng T. H., Patil A. J., Mann S., Hollander A. P., Kafienah W.: Directing chondrogenesis of stem cells with specific blends of cellulose and silk. Biomacromolecules, 14, 1287-1298 (2013). https://doi.org/10.1021/bm301762p

[5] Watanabe K., Eto Y., Takano S., Nakamori S., Shibai H., Yamanaka S.: A new bacterial cellulose substrate for mammalian cell culture. Cytotechnology, 13, 107-144 (1993). https://doi.org/10.1007/BF00749937

[6] Courtenay J. C., Johns M. A., Galembeck F., Deneke C., Lanzoni E. M., Costa C. A., Scott J. L., Sharma R. I.: Surface modified cellulose scaffolds for tissue engineering. Cellulose, 24, 253-267 (2017). https://doi.org/10.1007/s10570-016-1111-y

[7] Mikulíková R., Švorčík V., Náhlík J., Sopuch T., Havelka P.: Cytocompatibility of surface ground PE doped with calcium salt of 6-carboxycellulose. Cellulose, 15, 473479 (2008).

https://doi.org/10.1007/s10570-007-9196-y

[8] Petersen N., Gatenholm P.: Bacterial cellulose-based materials and medical devices: Current state and perspectives. Applied Microbiology and Biotechnology, 91, 1277-1286 (2011). https://doi.org/10.1007/s00253-011-3432-y

[9] Zaborowska M., Bodin A., Bäckdahl H., Popp J., Goldstein A., Gatenholm P.: Microporous bacterial cellulose as a potential scaffold for bone regeneration. Acta Biomaterialia, 6, 2540-2547 (2010).

https://doi.org/10.1016/j.actbio.2010.01.004

[10] Khan S., Ul-Islam M., Ikram M., Ul Islam S., Ullah M. W., Israr M., Jang J. H., Yoon S., Park J. K.: Preparation and structural characterization of surface modified microporous bacterial cellulose scaffolds: A potential material for skin regeneration applications in vitro and in vivo. International Journal of Biological Macromolecules, 117, 1200-1210 (2018).

https://doi.org/10.1016/j.ijbiomac.2018.06.044

[11] Novotna K., Havelka P., Sopuch T., Kolarova K., Vosmanska V., Lisa V., Svorcík V., Bacákova L.: Cellulose-based materials as scaffolds for tissue engineering. Cellulose, 20, 2263-2278 (2013). https://doi.org/10.1007/s10570-013-0006-4

[12] Rubenstein D. A., Venkitachalam S. M., Zamfir D., Wang F., Lu H., Frame M. D., Yin W.: In vitro biocompatibility of sheath-core cellulose-acetate-based electrospun scaffolds towards endothelial cells and platelets. Journal of Biomaterials Science, 21, 1713-1736 (2010). https://doi.org/10.1163/092050609X12559317149363

[13] Kingkaew J., Jatupaiboon N., Sanchavanakit N., Pavasant P., Phisalaphong M.: Biocompatibility and growth of human keratinocytes and fibroblasts on biosynthesized cellulose-chitosan film. Journal of Biomaterials Science, 21, 1009-1021 (2010). https://doi.org/10.1163/156856209X462763 
[14] Poncin-Epaillard F., Legeay G., Brosse J-C.: Plasma modification of cellulose derivatives as biomaterials. Journal of Applied Polymer Science, 44, 1513-1522 (1992). https://doi.org/10.1002/app.1992.070440903

[15] Kolářová K., Vosmanská V., Rimpelová S., Švorčík V.: Effect of plasma treatment on cellulose fiber. Cellulose, 20, 953-961 (2013). https://doi.org/10.1007/s10570-013-9863-0

[16] Pertile R. A. N., Andrade F. K., Alves C., Gama M.: Surface modification of bacterial cellulose by nitrogencontaining plasma for improved interaction with cells. Carbohydrate Polymers, 82, 692-698 (2010).

https://doi.org/10.1016/j.carbpol.2010.05.037

[17] Kamide K.: Cellulose and cellulose derivatives. Elsevier, Amsterdam (2005). https://doi.org/10.1016/B978-0-444-82254-3.X5000-0

[18] Heinze T., Petzold-Welcke K.: A sustainable approach to the development of renewable biomaterials. in 'Polysaccharide building blocks' (eds.: Habibi Y., Luci L. A.) Wiley, Hoboken, Vol. 1, 1-50 (2012).

[19] Shokri J., Adibkia K.: Application of cellulose derivatives in pharmaceutical industries. in 'Cellulose - medical, pharmaceutical and electronic applications' (eds.: van de Ven T., Godbout L.) IntechOpen, London, Vol. 1, 47-66 (2013).

[20] Vosmanská V., Kolářová K., Pišlová M., Švorčík V.: Chemical and physical modification of cellulosic biomaterials. Chemické Listy, 111, 614-621 (2017).

[21] Navard P.: The european polysaccharide network of excellence (EPNOE): Research initiatives and results. Springer, Wien (2012).

[22] Jedvert K., Heinze T.: Cellulose modification and shaping - A review. Journal of Polymer Engineering, 37, 845-860 (2017).

https://doi.org/10.1515/polyeng-2016-0272

[23] Märtson M., Viljanto J., Hurme T., Saukko P.: Biocompatibility of cellulose sponge with bone. European Surgical Research, 30, 426-432 (1998).

https://doi.org/10.1159/000008609

[24] Pulkkinen H., Tiitu V., Lammentausta E., Hämäläinen E. R., Kiviranta I., Lammi M. J.: Cellulose sponge as a scaffold for cartilage tissue engineering. Bio-Medical Materials and Engineering, 16, 29-35 (2006).

[25] Müller F. A., Müller L., Hofmann I., Greil P., Wenzel M. M., Staudenmaier R.: Cellulose-based scaffold materials for cartilage tissue engineering. Biomaterials, 27, 3955-3963 (2006). https://doi.org/10.1016/j.biomaterials.2006.02.031

[26] Vinatier C., Gauthier O., Fatimi A., Merceron C., Masson M., Moreau A., Moreau F., Fellah B., Weiss P., Guicheux J.: An injectable cellulose-based hydrogel for the transfer of autologous nasal chondrocytes in articular cartilage defects. Biotechnology and Bioengineering, 102, 1259-1267 (2009).

https://doi.org/10.1002/bit.22137
[27] Ko I. K., Iwata H.: An approach to constructing threedimensional tissue. Annals of the New York Academy of Sciences, 944, 443-455 (2001). https://doi.org/10.1111/j.1749-6632.2001.tb03854.x

[28] Entcheva E., Bien H., Yin L., Chung C-Y., Farrell M., Kostov Y.: Functional cardiac cell constructs on cellulose-based scaffolding. Biomaterials, 25, 5753-5762 (2004). https://doi.org/10.1016/j.biomaterials.2004.01.024

[29] Petzold-Welcke K., Michaelis N., Heinze T.: Unconventional cellulose products through nucleophilic displacement reactions. Macromolecular Symposia, 280, 72-85 (2009).

https://doi.org/10.1002/masy.200950609

[30] Bačáková L., Novotná K., Pařízek M.: Polysaccharides as cell carriers for tissue engineering: The use of cellulose in vascular wall reconstruction. Physiological Research, 63, 29-47 (2004).

[31] Lin N., Dufresne A.: Nanocellulose in biomedicine: Current status and future prospect. European Polymer Journal, 59, 302-325 (2014). https://doi.org/10.1016/j.eurpolymj.2014.07.025

[32] Kargarzadeh H., Huang J., Lin N., Ahmad I., Mariano M., Dufresne A., Thomas S., Gałęski, A.: Recent developments in nanocellulose-based biodegradable polymers, thermoplastic polymers, and porous nanocomposites. Progress in Polymer Science, 87, 197-227 (2018). https://doi.org/10.1016/j.progpolymsci.2018.07.008

[33] Märtson M., Viljanto J., Hurme T., Laippala P., Saukko P.: Is cellulose sponge degradable or stable as implantation material? An in vivo subcutaneous study in the rat. Biomaterials, 20, 1989-1995 (1999). https://doi.org/10.1016/S0142-9612(99)00094-0

[34] Yabu H.: Fabrication of honeycomb films by the breath figure technique and their applications. Science and Technology of Advanced Materials, 19, 802-822 (2018). https://doi.org/10.1080/14686996.2018.1528478

[35] Park J-J., Lee J-G., Kim D-Y., Hong J-H., Kim J-J., Hong S., Yoon S. S.: Antibacterial and water purification activities of self-assembled honeycomb structure of aerosol deposited titania film. Environmental Science and Technology, 46, 12510-12518 (2012). https://doi.org/10.1021/es3037252

[36] Chaudhuri J. B., Davidson M. G., Ellis M. J., Jones M. D., Wu X.: Fabrication of honeycomb-structured poly (DL-lactide) and poly[(DL-lactide)-co-glycolide)] films and their use as scaffolds for osteoblast-like cell culture. Macromolecular Symposia, 272, 52-57 (2008). https://doi.org/10.1002/masy.200851206

[37] Itoh H., Aso Y., Furuse M., Noishiki Y., Miyata T.: A honeycomb collagen carrier for cell culture as a tissue engineering scaffold. Artificial Organs, 25, 213-217 (2001). https://doi.org/10.1046/j.1525-1594.2001.025003213.x 
[38] Sunami H., Ito E., Tanaka M., Yamamoto S., Shimomura M.: Effect of honeycomb film on protein adsorption, cell adhesion and proliferation. Colloids and Surfaces A: Physicochemical and Engineering Aspects, 284, 548-551 (2006).

https://doi.org/10.1016/j.colsurfa.2005.11.041

[39] Zhuang C., Shi C., Tao F., Cui Y.: Honeycomb structural composite polymer network of gelatin and functional cellulose ester for controlled release of omeprazole. International Journal of Biological Macromolecules, 105, 1644-1653 (2017).

https://doi.org/10.1016/j.ijbiomac.2017.01.019

[40] Kasai W., Kondo T.: Fabrication of honeycomb-patterned cellulose films. Macromolecular Bioscience, 4, 17-21 (2004).

https://doi.org/10.1002/mabi.200300054

[41] Nemoto J., Uraki Y., Kishimoto T., Sano Y., Funada R., Obata N., Yabu H., Tanaka M., Shimomura M.: Production of mesoscopically patterned cellulose film. Bioresource Technology, 96, 1955-1958 (2005).

https://doi.org/10.1016/j.biortech.2005.01.034

[42] Uraki Y., Tamai Y., Hirai T., Koda K., Yabu H., Shimomura M.: Fabrication of honeycomb-patterned cellulose material that mimics wood cell wall formation processes. Materials Science and Engineering: C, 31, 1201-1208 (2011). https://doi.org/10.1016/j.msec.2010.11.009

[43] Yu B., Cong H., Li Z., Yuan H., Peng Q., Chi M., Yang S., Yang R., Wickramasinghe S. R., Tang J.: Fabrication of highly ordered porous membranes of cellulose triacetate on ice substrates using breath figure method. Journal of Polymer Science Part B: Polymer Physics, 53, 552-558 (2015).

https://doi.org/10.1002/polb.23667

[44] Hamano F., Seki H., Ke M., Gopiraman M., Lim C. T., Kim I. S.: Cellulose acetate nanofiber mat with honeycomb-like surface structure. Materials Letters, 169, 33 36 (2016).

https://doi.org/10.1016/j.matlet.2015.11.069

[45] Dou Y., Jin M., Zhou G., Shui L.: Breath figure method for construction of honeycomb films. Membranes, $\mathbf{5}$, 399-424 (2015).

https://oi.org/10.3390/membranes5030399

[46] Zhang A., Bai H., Li L.: Breath figure: A nature-inspired preparation method for ordered porous films. Chemical Reviews, 115, 9801-9868 (2015).

https://doi.org/10.1021/acs.chemrev.5b00069

[47] Bui V-T., Tran Q. C., Nguyen V-T., Dao V-D., Choi J. S., Choi H-S.: Ordered honeycomb biocompatible polymer films via a one-step solution-immersion phase separation used as a scaffold for cell cultures. Chemical Engineering Journal, 320, 561-569 (2017).

https://doi.org/10.1016/j.cej.2017.03.086

[48] Slepička P., Neznalová K., Fajstavr D., Slepičková Kasálková N., Švorčík V.: Honeycomb-like pattern formation on perfluoroethylenepropylene enhanced by plasma treatment. Plasma Processes and Polymers, 16, 1900063/1-1900063/6 (2019).

https://doi.org/10.1002/ppap.201900063
[49] Slepička P., Trostová S., Slepičková Kasálková N., Kolská Z., Sajdl P., Švorčík V.: Surface modification of biopolymers by argon plasma and thermal treatment. Plasma Processes and Polymers, 9, 197-206 (2012). https://doi.org/10.1002/ppap.201100126

[50] Rimpelová S., Slepičková Kasálková N., Slepička P., Lemerová H., Švorčík V., Ruml T.: Plasma treated polyethylene grafted with adhesive molecules for enhanced adhesion and growth of fibroblasts. Materials Science and Engineering: C, 33, 1116-1124 (2013).

https://doi.org/10.1016/j.msec.2012.12.003

[51] Slepička P., Malá Z., Rimpelová S., Slepičková Kasálková N., Švorčík V.: Plasma treatment of the surface of poly(hydroxybutyrate) foil and non-woven fabric and assessment of the biological properties. Reactive and Functional Polymers, 95, 71-79 (2015).

https://doi.org/10.1016/j.reactfunctpolym.2015.08.010

[52] Slepička P., Michaljaničová I., Sajdl P., Fitl P., Švorčík V.: Surface ablation of PLLA induced by $\mathrm{KrF}$ excimer laser. Applied Surface Science, 283, 438-444 (2013). https://doi.org/10.1016/j.apsusc.2013.06.127

[53] Slepička P., Slepičková Kasálková N., Siegel J., Kolská Z., Bačáková L., Švorčík V.: Nano-structured and functionalized surfaces for cytocompatibility improvement and bactericidal action. Biotechnology Advances, 33, 1120-1129 (2015). https://doi.org/10.1016/j.biotechadv.2015.01.001

[54] Slepička P., Siegel J., Lyutakov O., Slepičková Kasálková N., Kolská Z., Bačáková L., Švorčík V.: Polymer nanostructures for bioapplications induced by laser treatment. Biotechnology Advances, 36, 839-855 (2018). https://doi.org/10.1016/j.biotechadv.2017.12.011

[55] Slepička P., Peterková L., Rimpelová S., Pinkner A., Slepičková Kasálková N., Kolská Z., Ruml T., Švorčík V.: Plasma activated perfluoroethylenepropylene for cytocompatibility enhancement. Polymer Degradation and Stability, 130, 277-287 (2016). https://doi.org/10.1016/j.polymdegradstab.2016.06.017

[56] Liu W., Zhou Z., Liao X., Li C., Tang H., Xie M., Chen Y., Zeng G.,He Y., Liu Y.: Tailoring ordered microporous structure of cellulose-based membranes through molecular hydrophobicity design. Carbohydrate Polymers, 229, 115425/1-115425/11 (2020).

https://doi.org/10.1016/j.carbpol.2019.115425

[57] Xu W. Z., Bar-Nir B. B-A., Kadla J. F.: Honeycomb membranes prepared from 3-O-amino acid functionalized cellulose derivatives. Carbohydrate Polymers, 100, 126-134 (2014).

https://doi.org/10.1016/j.carbpol.2012.12.076

[58] Dong F., Yan M., Jin C., Li S.: Characterization of typeII acetylated cellulose nanocrystals with various degree of substitution and its compatibility in PLA films. Polymers, 9, 346/1-346/14 (2017).

https://doi.org/10.3390/polym9080346 